\title{
Phosphorylated Silk Fibroin Matrix for Methotrexate Release
}

\author{
Vadim Volkov, ${ }^{\dagger}$ Marisa P. Sárria, ${ }^{\dagger}+$ Andreia C. Gomes, $^{\dagger}$ and Artur Cavaco-Paulo ${ }^{*}{ }^{\dagger}$ \\ ${ }^{\dagger}$ Centro de Engenharia Biológica (CEB), Universidade do Minho, Campus de Gualtar, 4710-057 Braga, Portugal \\ ${ }^{\ddagger}$ Centro de Biologia Molecular e Ambiental (CBMA), Departamento de Biologia, Universidade do Minho, Campus de Gualtar, \\ 4710-057 Braga, Portugal
}

\section{Supporting Information}

ABSTRACT: Silk-based matrix was produced for delivery of a model anticancer drug, methotrexate (MTX). The calculation of net charge of silk fibroin and MTX was performed to better understand the electrostatic interactions during matrix formation upon casting. Silk fibroin films were cast at $\mathrm{pH}$ 7.2 and $\mathrm{pH}$ 3.5. Protein kinase $\mathrm{A}$ was used to prepare phosphorylated silk fibroin. The phosphorylation content of matrix was controlled by mixing at specific ratios the phosphorylated and unphosphorylated solutions. In vitro

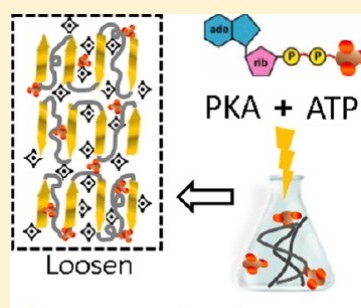

of Incoming phospho-group $\{$ Random-coils | $\beta$-sheets \& MTX release profiling data suggest that the observed interactions are mainly structural and not electrostatical. The release of MTX is facilitated by use of proteolytic enzymes and higher pHs. The elevated $\beta$-sheet content and crystallinity of the acidified-cast fibroin solution seem not to favor drug retention. All the acquired data underline the prevalence of structural interactions over electrostatical interactions between methotrexate and silk fibroin.

KEYWORDS: silk fibroin, phosphorylation, methotrexate, DLS, net charge

\section{INTRODUCTION}

In the past decades considerable attention has been drawn toward the production of biocompatible and bioinspired materials based on silk fibroins. ${ }^{1}$ Silk possesses remarkable properties such as high mechanical strength, low degradability, and immunogenicity. ${ }^{1}$ Silk is a material of choice for many applications, because it is easily isolated from source cocoons and can be processed to obtain a variety of morphologically different devices. ${ }^{2}$ Examples include silk-based materials for tissue regeneration, ${ }^{3}$ drug delivery systems, ${ }^{4}$ and modulation of host immune responses ${ }^{5}$ among others.

As a tool of material engineering, phosphorylation remains largely unexplored. Yet, in nature, phosphorylation plays a fundamental role in protein stabilization and allosteric control. ${ }^{6}$ Thus, phosphorylation can be used as a tool to develop new materials. In a previous work, ${ }^{7}$ modulation of hydrophobicity and crystalline content of silk fibroin based materials was done through in vitro phosphorylation of regenerated silk using the protein kinase A (PKA). It is known that, under physiological conditions, the phospho-Ser residues of a protein bear a double negative charge 8 which considerably influences their microenvironment. ${ }^{9}$ A correlation between phospho-Ser amount and the physicochemical properties of the produced films was observed, due to increased negative charge and loosened structure of phosphorylated chains.

Methotrexate (MTX) is a known folate antagonist, applied in chemotherapy for a broad range of human malignancies (those overexpressing folate receptors on their surfaces ${ }^{10}$ ). MTX usage, however, may be restricted due to undesired side effects, like the toxicity to hematopoietic and gastrointestinal tissues ${ }^{11}$ and nephrotoxicity. ${ }^{12}$ Eventually, cancer cells may acquire resistance to MTX by different mechanisms, mostly by a defective transport of the drug, ${ }^{13}$ thus compromising its therapeutic effect.

Hence, the emerged idea of controlled release of antitumor agents poses attraction as it allows for a more uniform and prolonged level of a circulating drug, accordingly lessening the negative side effects. The efficiency of MTX and similar compounds that require prolonged administration of the drug for efficient cancer treatment is increased. Various strategies of MTX-containing formulations for medical research are currently being attempted. Among several, the injectable, thermosensitive polymeric hydrogels for intra-articular delivery; ${ }^{14}$ combined magnetite-chitosan microspheres; ${ }^{15}$ and gelatin-based $^{16}$ and chitosan-based ${ }^{17}$ nanoparticles have been prepared. Other carrier systems of MTX delivery are known: a nanostructured lipid carrier ${ }^{18}$ and a sophisticated dextranpeptide-MTX autocleaved conjugate construct. ${ }^{19}$ In this context, materials for controlled delivery and/or release of MTX, based on silk fibroin, are described by solely one report of silk-albumin nanoparticles ${ }^{20}$ and two patents ${ }^{21,22}$ dealing with the same formulation type.

In this work we studied the effect of phosphorylation and the casting conditions on a solid matrix for the delivery of MTX. Casting was done at $\mathrm{pH} 3.5$ and $\mathrm{pH} 7.2$ when both MTX and

Received: June 19, 2014

Revised: November 17, 2014

Accepted: November 29, 2014

Published: November 29, 2014 
phosphorylated fibroin have similar charges. Initially, theoretical net charge of silk as a function of phosphorylation level and the $\mathrm{pH}$ of resulting solution was estimated. For MTX the charge was also estimated throughout the range of discrete $\mathrm{pH}$ values. Later, by combining dynamic light scattering (DLS) ${ }^{23}$ and electrophoretic mobility measurements, ${ }^{24}$ the empirical net charges of both compounds were determined. Differential scanning calorimetry (DSC) and release profiling of MTX from the polymeric matrixes of silk fibroin were performed to elucidate the nature of interactions between both molecules. A hypothesis of prolonged release of MTX from films of different hydrophobicity and varying incubation buffer conditions was empirically examined. A trial was made to find, in terms of $\mathrm{pH}$, a favorable condition for polymer-drug interactions (whether structural or electrostatic, or both) to be used in solution-cast fibroin film production.

\section{MATERIALS AND METHODS}

2.1. Materials. Silk cocoons from Bombyx mori were supplied from "Sezione Specializzata per la Bachicoltura" (Padova, Italy). Kinase-GLO luminescent kinase assay kit (Cat. No. V6712) and CellTiter 96 Aqueous One Solution were obtained from Promega Corporation, USA. Tissue culture test microplates were from TPP Techno Plastic Products AG, Switzerland, and Whatman grade 2 filter paper (Cat. No. 1002070) was from Whatman, USA.

2.2. Preparation of Silk Fibroin Solution. Sericin content was removed from the silk as described elsewhere. ${ }^{25}$ Fibroin solution of final $2 \mathrm{wt} \%$ was prepared. The concentration of silk fibroin was assessed via the dry weight method on Whatman paper, in triplicate.

2.3. Preparation of Phospho-Silk Fibroin Films and MTX Loading. Dialyzed raw silk fibroin solution was phosphorylated using protein kinase A (EC 2.7.1.37) as

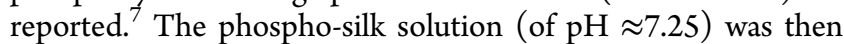
divided and the $\mathrm{pH}$ of one part adjusted to $\approx 3.5$ using a $50 \%$ aqueous $\mathrm{HCl}$. Consequently, kinase reaction buffer was added to the unreacted, raw fibroin solution, and the mixture $\mathrm{pH}$ was adjusted to $\approx 3.5$ value, or left untreated. Finally, the desired blends, containing various amounts of phospho-silk fibroin content and of two $\mathrm{pH}$ values, were prepared by casting and mixing the appropriate quantities of unmodified fibroin and phospho-fibroin solutions in a 24-well plate. $60 \mu \mathrm{L}$ of MTX stock solution was added, so that the drug final concentration of $0.2 \mathrm{mg} \mathrm{mL}^{-1}$ was established. Control samples were cast without MTX. Cast solutions of $3 \mathrm{~mL}$ volume were left for drying under constant air flow in a laminar flow hood for 2 to 3 days at room temperature. Dry film thickness (at the bottom) was measured using a caliper.

2.4. Quantitative Determination of Phosphate Incorporated in Phospho-Silk Fibroin. Phosphate amounts were determined according to the previously established protocol. $^{7}$

2.5. DLS and Electrophoretic Measurements of Silk Fibroin and MTX. DLS was performed on a Zetasizer Nano SZ instrument, run under Zetasizer Software v.7.02 (Malvern, U.K.). Samples were equilibrated at $25{ }^{\circ} \mathrm{C}$ for $2 \mathrm{~min}$ prior to measurements. For $0.5 \mathrm{~g} \mathrm{~L}^{-1} \mathrm{MTX}$, the material definition was "polystyrene latex in water solvent" (all predefined by Malvern). For silk fibroin the material was chosen as "protein" (predefined by Malvern), but the solvent was determined as "silk fibroin solution" (a user-created, custom pattern). Two constants were introduced for this "solution": refractive index,
$\mathrm{Ri}_{\mathrm{SF}}$, and solution viscosity, $\eta_{\mathrm{SF}}$. $\mathrm{Ri}_{\mathrm{SF}}$ was measured for 2 wt $\%$ proteinaceous solution using an ATAGO RX-9000X refractometer (ATAGO Co., USA), resulting in a value of $1.335 . \eta_{\mathrm{SF}}$ was theoretically estimated from the rearranged equation for the intrinsic viscosity, $[\eta]:^{26}$

$$
[\eta] \equiv \frac{\ln \left(\eta_{\mathrm{SF}} / \eta_{\mathrm{S}}\right)}{C_{\mathrm{SF}}}
$$

where $\eta_{\mathrm{S}}$ is the viscosity of solvent, i.e., water, with the value of $0.8872 \mathrm{cP}$ and $C_{\mathrm{SF}}$ is the fibroin solution concentration. The value of $[\eta]$ was previously given ${ }^{26}$ as $0.23{C_{\mathrm{SF}}}^{-1}$, so that one obtains $\eta_{\mathrm{SF}}=1.4054 \mathrm{cP}$. For net charge estimations, involving DLS, the results of forward scattering were exclusively used.

Electrophoretic mobility measurements were carried out on the same equipment. Malvern disposable capillary cells of DTS1070 type were used for both measurement kinds. All the measurements were performed in triplicate.

2.6. Net Charge Estimations of Silk Fibroin and MTX. Effective valence, or net charge, values were calculated via a stepwise process. Initially, a hydrodynamic radius, $R_{\mathrm{H}}$, of material of interest was measured by DLS. Subsequently, $D_{0}$, was calculated from the rearranged Stokes-Einstein relationship:

$$
D_{0}=\frac{k_{\mathrm{B}} T}{6 \pi \eta_{\mathrm{S}} R_{\mathrm{H}}}
$$

where $k_{\mathrm{B}}$ is the Boltzmann constant, $\eta_{\mathrm{S}}$ is the solvent (and, for the case of silk fibroin, the solution) viscosity, $T$ is the temperature, and $D_{0}$ is the diffusion coefficient. Separately measuring the electrophoretic mobility, $\mu$, and substituting $D_{0}$ and $\mu$ values into the equation of apparent valence $z$,

$$
z=\frac{\mu k_{\mathrm{B}} T}{D_{0} e}
$$

where $e$ is the elementary charge, gives the final result. ${ }^{24}$

Theoretical estimation of net charge for both compounds was performed by the calculation of individual acid/basederived charges, corresponding to specific $\mathrm{p} K_{a}$ using the Henderson-Hasselbalch equation.

2.7. Thermal Analysis of Silk Fibroin Derived Materials. DSC measurements were performed with a NETZSCH-DSC 200F3 instrument (Netzsch GmBH). The experimental program consisted of sample pretreatment and the measurement itself. Pretreatment included heating from room temperature to $120{ }^{\circ} \mathrm{C}$ and holding the temperature for $10 \mathrm{~min}$ to induce sample dehydration. The temperature was then lowered to $25{ }^{\circ} \mathrm{C}$. From this point it was increased to 300 ${ }^{\circ} \mathrm{C}$, and the measurement was performed. Constant energy flow rate of $10{ }^{\circ} \mathrm{C} \mathrm{min}^{-1}$ was used in all steps. In the case of MTX addition, its averaged weight was $0.431 \pm 0.077 \mathrm{mg}$. Average total sample weight was $2.28 \pm 0.63 \mathrm{mg}$. During the analysis the aluminum cell was swept with $50 \mathrm{~mL} \min ^{-1} \mathrm{~N}_{2}$ flow.

2.8. In Vitro Release. The release kinetics of MTX in two different solutions (PBS, $0.1 \mathrm{M}$; ammonium bicarbonate, $\mathrm{NH}_{4} \mathrm{HCO}_{3}, 0.1 \mathrm{M}$ ) and two different $\mathrm{pH}$ values (6.25 and 8.0) was studied. Both $\mathrm{pH}$ values are applicable to PBS and $\mathrm{NH}_{4} \mathrm{HCO}_{3}$ solutions. The discrete $\mathrm{pH}$ values were chosen according to the Sigma-Aldrich product datasheet (code E0127), defining that $\mathrm{pH} \mathrm{8.0-8.5} \mathrm{is} \mathrm{optimal} \mathrm{for} \mathrm{the} \mathrm{protease.}$ Hence a lesser enzymatic activity was anticipated for the lower $\mathrm{pH}$. Silk fibroin derived materials were incubated at $37{ }^{\circ} \mathrm{C}$ in 
the aforementioned solutions, of which only $\mathrm{NH}_{4} \mathrm{HCO}_{3}$ contained a protease, porcine pancreatic elastase (PPE, EC 3.4.21.36) at 1:100 elastase:substrate $\mathrm{w} / \mathrm{w}$ ratio. At determined time points, MTX release was quantified by absorbance measurements at $403 \mathrm{~nm}$ against a standard absorbance curve. To obtain kinetic values characterizing different conditions and materials, incubation during $4 \mathrm{~h}$ with $20 \mathrm{~min}$ sampling was done. The buffers were flashed each hour. The release behavior of MTX from polymeric systems was determined by fitting the experimental data as described. ${ }^{7}$ Ritger-Peppas- and Higuchi-derived constants were designated as $K_{\mathrm{RP}}$ and $K_{\mathrm{H}}$, accordingly. The fitting was performed in OriginPro software, v8.5.0 (OriginLab Corporation, USA), using "Linear fit" routine.

2.9. Cell Culture. The human intestinal Caco-2 cell line (ATCC HTB37) was maintained under a humidified atmosphere containing $5 \% \mathrm{CO}_{2}$ at $37{ }^{\circ} \mathrm{C}$, in high glucose Dulbecco's modified Eagle medium (DMEM) with L-glutamine and $1 \%$ nonessential amino acids, supplemented with $20 \%$ heatinactivated fetal bovine serum (FBS) and $1 \%$ antibiotic/ antimycotic solution (10000 units $\mathrm{mL}^{-1}$ penicillin, $10000 \mu \mathrm{g}$ $\mathrm{mL}^{-1}$ streptomycin, $25 \mu \mathrm{g} \mathrm{mL}^{-1}$ amphotericin).

2.10. Cell Proliferation Assay. MTS compound, in the presence of phenazine ethosulfate, is bioreduced by cells into a soluble formazan product with an absorbance maximum at 490 $\mathrm{nm}$, thus assaying active cell metabolism. ${ }^{27}$ CellTiter 96 Aqueous One Solution, containing MTS, was used to assess cell viability. Triplicates for each individual assay were considered.

2.10.1. Test by Indirect Contact. (Phospho-) silk fibroin films were disinfected by triple washings with antibiotic/ antimycotic solution and preconditioned with culture medium devoid of FBS for $6 \mathrm{~h}$ at $37^{\circ} \mathrm{C}$. The medium was later harvested and supplemented with $10 \%$ serum. This preconditioned medium was then applied to previously seeded $\left(1 \times 10^{5}\right.$ cells $\mathrm{mL}^{-1}$ ) and adhered Caco- 2 cells. The cells were further incubated for $48 \mathrm{~h}$, and the proliferation was assessed with MTS. The assay was performed in duplicate.

2.11. Statistical Analysis. All assumptions were met prior to data analysis. To investigate the kinetic modeling of MTX release among different $\mathrm{pH}$ cast silk fibroin films, the dissolution constants of Higuchi $\left(K_{\mathrm{H}}\right)$ and Ritger-Peppas $\left(K_{\mathrm{RP}}\right)$ mathematical models were considered. These kinetic values were determined using different strategies $\left(K_{\mathrm{H}}\right.$, by fitting software; $K_{\mathrm{RP}}$, by fitting and subsequent calculation), therefore, distinguished statistical methods were applied for drug release profile comparisons. A factorial ANOVA [three factors: $\mathrm{pH}$ of cast-film (two levels: $\mathrm{pH} 7.2$ and $\mathrm{pH} 3.5$ ); type of film matrix (four levels: $0,15,30,60 \%$ of serine residue modification), and type of incubation solution (four levels: $\mathrm{PBS} \mathrm{pH}$ 8.0, PBS $\mathrm{pH}$ 6.25, $\mathrm{PPE} \mathrm{pH} 8.0$, and $\mathrm{PPE} \mathrm{pH} 6.25)$ ] was conducted to evaluate the influence of $\mathrm{pH}$ on release rate of MTX-loaded SFfilms, considering the Ritger-Peppas kinetic values. $t$ test for independent groups was applied to determine the influence of $\mathrm{pH}$ on release rate of MTX-loaded SF-films, considering the Higuchi kinetic values. Wilcoxon matched pairs test was considered to compare the kinetic profile of MTX-loaded SFfilms among mathematical models.

ANOVA analysis [two factors: $\mathrm{pH}$ of cast-film (two levels: $\mathrm{pH} 7.2$ and $\mathrm{pH} 3.5$ ) and type of film matrix (four levels: 0, 15, $30,60 \%$ of serine residue modification)] was conducted to investigate the influence of the MTX-loaded SF-film modification degree (of serine residues) on cell proliferation.
Post hoc comparisons were conducted using StudentNewman-Keuls (SNK). A $P$ value of 0.05 was used for significance testing. Analyses were performed in STATISTICA (v.7)

\section{RESULTS}

3.1. (Phospho-) Silk Fibroin Solutions: Production and Net Charge Estimation. Phosphorylation of initial silk fibroin solution was made using the developed protocol and resulted in $\approx 60 \%$ of phosphorylation after 3-4 h. The phosphorylation $\%$ is the percent of all sites, suitable for enzymatic phosphorylation, that were successfully modified. ${ }^{7}$ Phosphorylation of Ser residues in fibroin was further analyzed by malachite green for their $\%$ of released maximal phosphate (Table 1 ).

Table 1. Evaluation of the Phosphorylated Content (Phospho-Ser) by Malachite Green Reaction for Different Silk Fibroin Blends ${ }^{a}$

\begin{tabular}{|c|c|c|c|}
\hline \multirow[b]{2}{*}{$\begin{array}{l}\text { phosphorylation } \\
\text { degree, } \%\end{array}$} & \multicolumn{3}{|c|}{$\begin{array}{l}\text { blends elaborated for the characterization/analysis of } \\
\text { type }\end{array}$} \\
\hline & DSC (batch 1) & $\begin{array}{l}\text { MTX release } \\
\text { (batch 2) }\end{array}$ & $\begin{array}{c}\text { cytotoxicity } \\
\text { (batch 3) }\end{array}$ \\
\hline 60 & $61.0 \pm 1.11$ & $59.95 \pm 4.96$ & $56.94 \pm 2.52$ \\
\hline 30 & $29.9 \pm 1.54$ & $30.67 \pm 2.4$ & $32.61 \pm 2.7$ \\
\hline 15 & $15.54 \pm 2.76$ & $16.32 \pm 2.64$ & $15.05 \pm 1.92$ \\
\hline
\end{tabular}

${ }^{a}$ The percentages denote phosphorylation extent of all possible sites. The current quantification was based on one assay (for each separate batch type) with double sampling. The calculated data represent the percentage from the maximally estimated value of inorganic phosphate $(\mathrm{Pi})$, released during phospho-Ser hydrolysis.

In an attempt to enhance MTX-fibroin electrostatic interactions and thus promote more prolonged drug release, we initially theoretically estimated the charges of both compounds as a function of $\mathrm{pH}$, and specifically to fibroin, also as a function of its phosphorylation. The rationale for doing this was the inability of existing tools to accurately calculate net charge $(z)$ of the phosphorylated protein. It can be seen that phosphorylation level inversely correlates with overall positive charge of a protein (Figure $\mathrm{S} 1$ in the Supporting Information). The $\mathrm{pH}$ range between 3.5 and 4.0 was of particular interest, since the extensively modified protein $(60 \%$ phosphorylated) and MTX possess opposite charges in that interval. With $\mathrm{pH}$ increment, both proteinaceous solution and the drug acquire negative charges, rendering electrostatic interactions less favorable. This trend of silk charge change is in agreement with the results obtained by in silico tools, available online (for example, Protein Calculator v3.4, http:// protcalc.sourceforge.net), applied on full protein sequence (accession number AF226688). To test the polymer-drug interactions, two discrete casting $\mathrm{pH}$ values were chosen: 3.5 and 7.2. Phosphorylated fibroin was produced, its $\mathrm{pH}$ value adjusted, and net charge calculated, while MTX charge was elucidated for two distinct $\mathrm{pH}$ values.

During the experimental estimation of net charges of both compounds, they demonstrated a positive $z$ values within acidic $\mathrm{pH}$ range (Figures 1 and $\mathrm{S} 2$ in the Supporting Information). This magnitude of charge is clearly seen for fibroin solution and, to a lesser extent, for MTX.

3.2. Optimization of Production of MTX-Loaded Films. Considering the desired effect of weaker electrostatic repulsion between fibroin and MTX, at acidic $\mathrm{pH}$, we cast 
A.

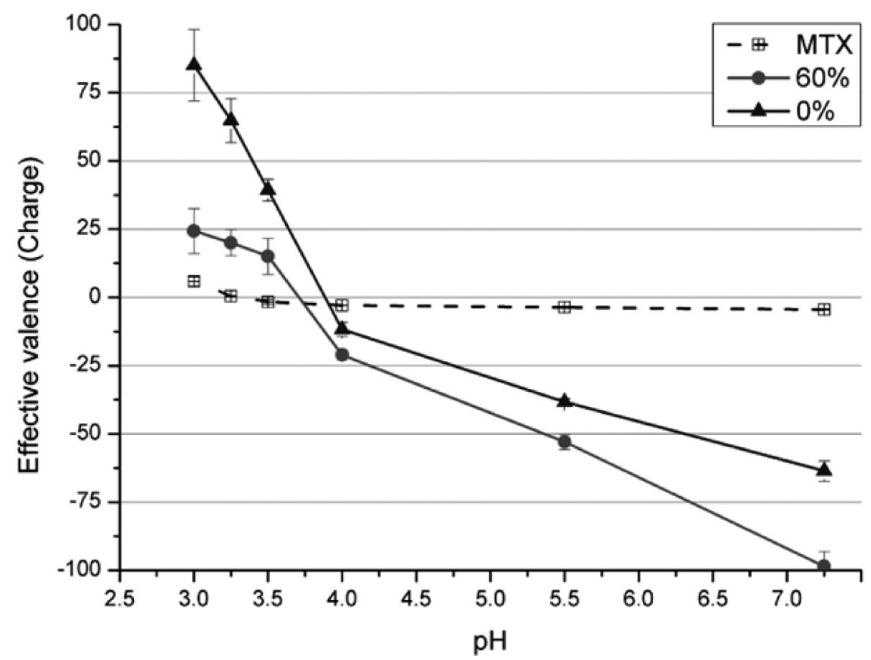

B.

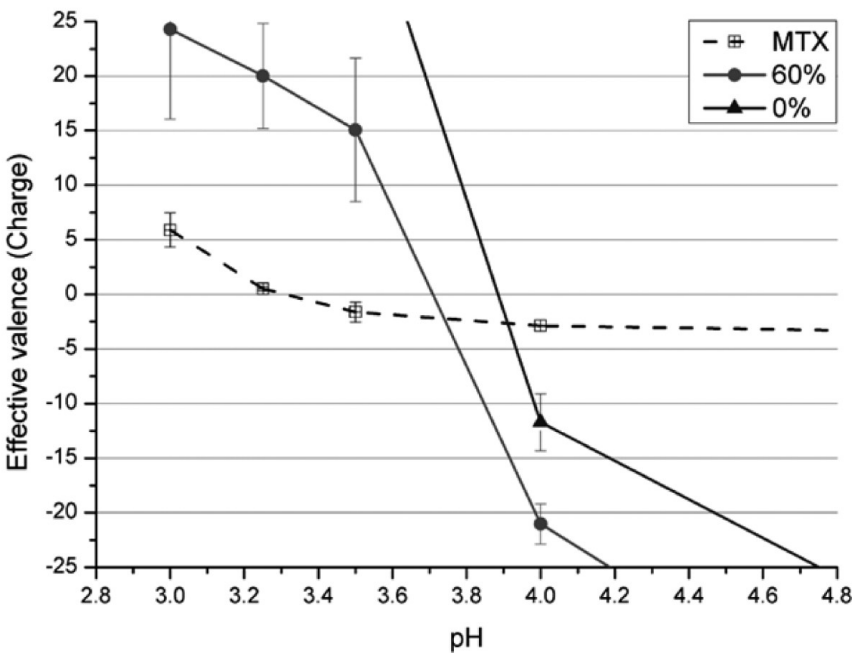

Figure 1. Experimental estimation of silk fibroin and methotrexate (MTX) charges as a function of pH. (A) Full-scale representation. (B) Zoomedin representation. The increase of negative charge resulting from phosphorylation is observed. For better clarity, additional curves, corresponding to material types $15 \%$ and $30 \%$ (appearing between $0 \%$ and $60 \%$ types), are provided as Supporting Information.
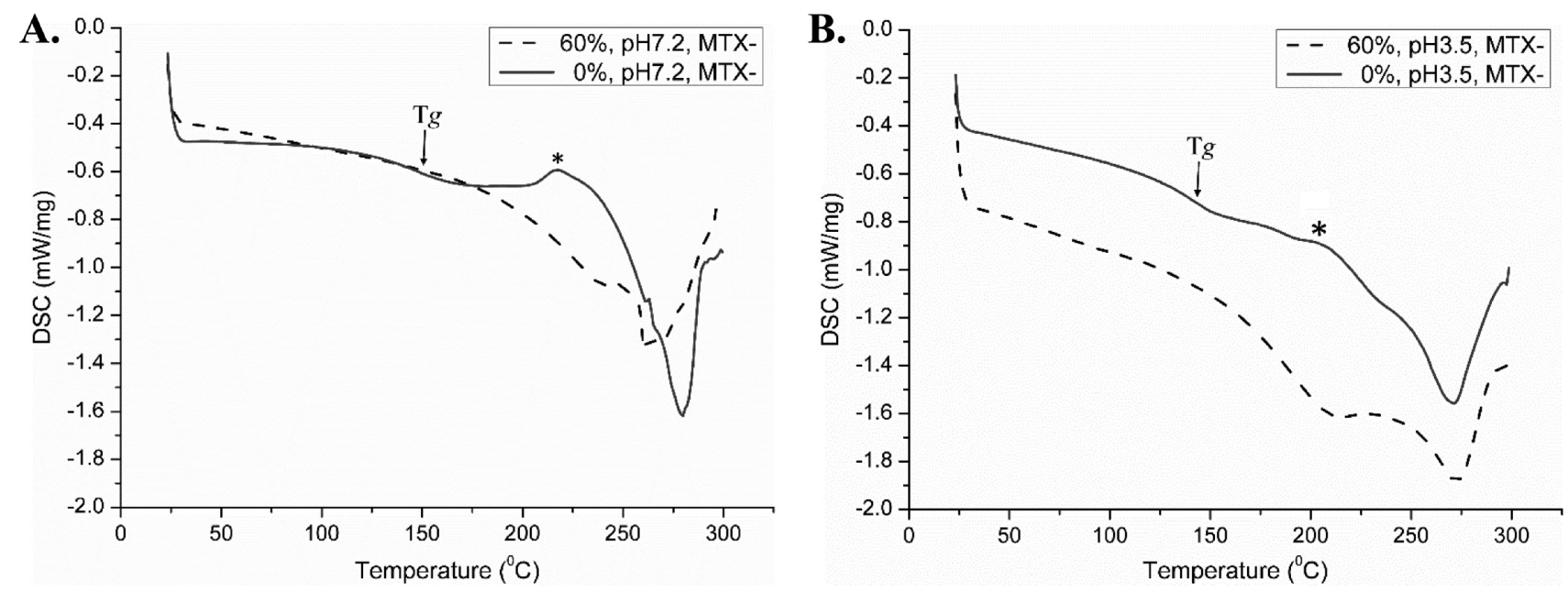

Figure 2. Thermal analysis of silk fibroin films, without ("MTX-") methotrexate embedded. (A) Fibroin films cast at pH 7.2. In panel ( A), the marked $\mathrm{Tg}$ applies to the material of $0 \%$ modification only. (B) Fibroin films cast at $\mathrm{pH}$ 3.5. Crystallization peaks are denoted by asterisks. Where possible, the onset temperature glass transition $\left(T_{\mathrm{g}}\right)$ is indicated.

proteinaceous solutions at two discrete $\mathrm{pH}$ values and added the drug. The first casting was performed at nearly neutral $\mathrm{pH}$ of 7.25 and the second at $\mathrm{pH}$ 3.5. During fibroin solution titration with $\mathrm{HCl}$, a protein loss of $\approx 3 \%$ from its soluble amount was detected. This happened due to the hydrophobic self-aggregation of silk, where the local $\mathrm{pH}$ drop (in the immediate environment of $\mathrm{HCl}$ ) was the most significant. ${ }^{28}$ To avoid the possible gelation of acidified silk solution during the drying process, considerable air flow is needed. In the current work, thicker films obtained by solvent casting in tissue culture test plates $\left(3 \mathrm{~mL}\right.$ of solution in a $3.29 \mathrm{~mL}$ well, of $7.45 \mathrm{~cm}^{2}$ bottom square) rendered methanol treatment (insolubility induction of dried materials) dispensable. "Thicker films" in this context have increased thickness, related to the previously employed approach, ${ }^{7}$ where $5 \mathrm{~mL}$ of solution was cast in a 10 $\mathrm{mL}$ Petri dish of $32.17 \mathrm{~cm}^{2}$ bottom square. The currently obtained films were of $0.08-0.12 \mathrm{~mm}$ or $0.12-0.16 \pm 0.03 \mathrm{~mm}$ thickness, originating from casting $\mathrm{pH}$ values of 3.5 and 7.2, respectively.
3.3. Thermal Analysis of Silk Fibroin Derived Films. The thermal analysis of silk fibroin derived films pursued two goals: to demonstrate structural differences of dried materials imposed by $\mathrm{pH}$ and phosphorylation, and to monitor existing interaction between fibroin and MTX. As seen in Figures 2 and 3 , in comparison to neutral $\mathrm{pH}$-cast films, acidic $\mathrm{pH}$ derived materials exhibit increased amount of $\beta$-sheet structures, resulting in the smoothening of thermogram curves. ${ }^{29}$ Silk fibroin glass transition temperature $\left(T_{\mathrm{g}}\right)$ characterizes a structural shift, preceding the formation of $\beta$-sheet arrangements. For the material cast at neutral $\mathrm{pH}$ with the following phosphorylation degree of $0 \%, 15 \%$, and $30 \%, T_{\mathrm{g}}$ onset was $\approx 135-145{ }^{\circ} \mathrm{C}$; a similar result was observed solely for the unmodified material (0\%), cast at acidic $\mathrm{pH}$ (Figures 2A and S3 in the Supporting Information). Thermodynamically, acidic $\mathrm{pH}$ favors silk self-aggregation, ${ }^{28}$ therefore $T_{\mathrm{g}}$ is not observed for $\mathrm{pH} 3.5$-cast films. A crystallization peak is only clearly evident for $0 \%$ phosphorylation for the $\mathrm{pH} 7.2$-cast film $\left(\approx 217^{\circ} \mathrm{C}\right.$; Figure $2 \mathrm{~A}$ ). Fainter crystallization events could still be observed 

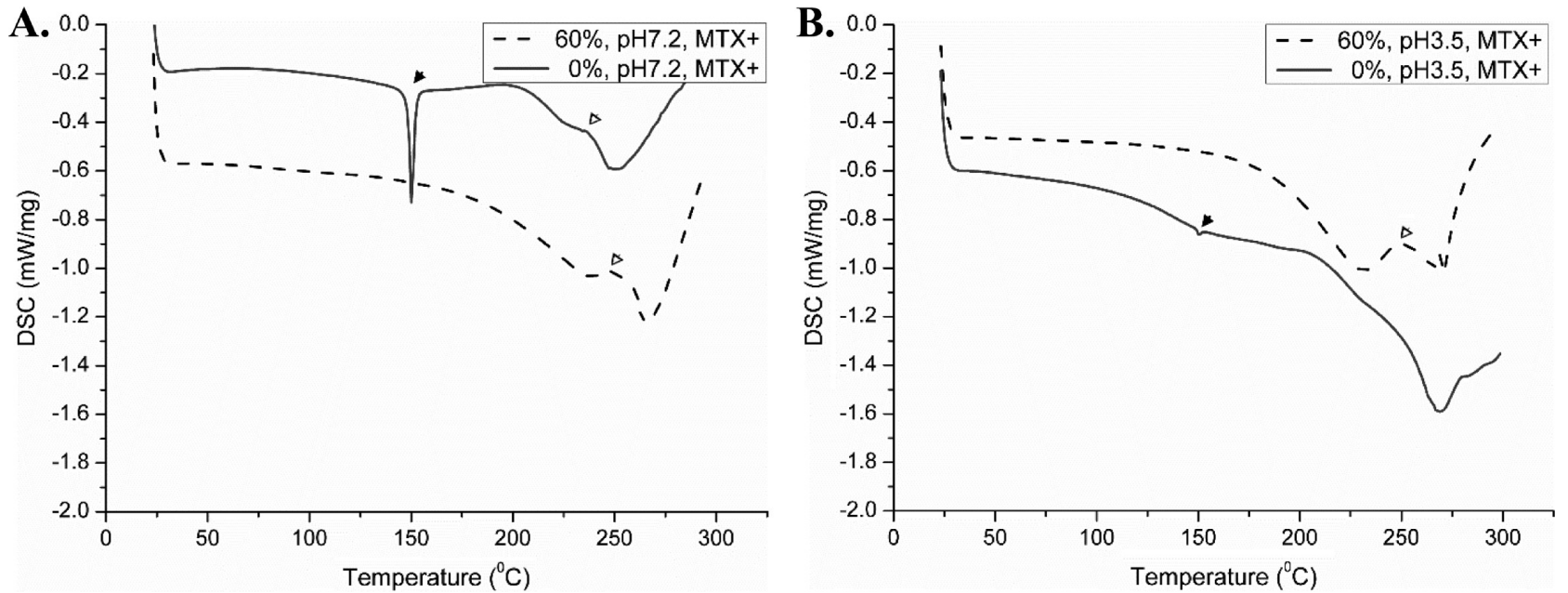

Figure 3. Thermal analysis of silk fibroin films, with ("MTX+") methotrexate embedded. (A) Fibroin films cast at pH 7.2. (B) Fibroin films cast at $\mathrm{pH}$ 3.5. Several, though not all, methotrexate-related peaks are denoted with arrows. Each arrow type $(\boldsymbol{\nabla}$, pseudomelting, or $\boldsymbol{D}$, recrystallization coupled to partial decomposition) corresponds to a distinct thermal event, resulting from the incorporated MTX.

for 0 and $15 \%$ phosphorylated matrices, cast at acidic and neutral $\mathrm{pH}$, respectively (Figures $2 \mathrm{~B}$ and $\mathrm{S} 3 \mathrm{C}$ in the Supporting Information). For all the materials at different phosphorylation degrees the decomposition occurs at $275{ }^{\circ} \mathrm{C}$. Some films presented a bimodal decomposition endotherm, ${ }^{30}$ as can be seen on Figures $2 \mathrm{~B}$ and $3 \mathrm{~B}$. This fact may be due to the nonuniformity of the material that causes stepwise energy absorption.

The DSC curve of MTX powder presents several distinct peaks (Figure 4 ). The first peak, at $\approx 175{ }^{\circ} \mathrm{C}$, can be attributed

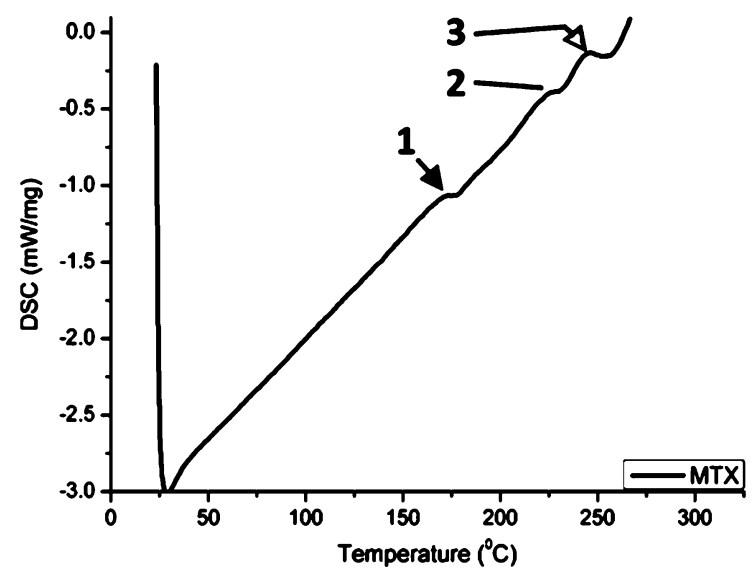

Figure 4. Representation of the DSC curve of methotrexate (MTX) powder. The three main thermal events are indicated: first $(>)$, pseudomelting; second (without special designation), solid-solid transition; third $(D)$, recrystallization coupled to partial decomposition. Due to the specificity of the used procedure (section 2.7), the MTX dehydration endotherm is not shown in the current presentation.

to pseudomelting or dissolution, ${ }^{31}$ while the second peak, at $\approx 224{ }^{\circ} \mathrm{C}$, is mainly due to solid-solid transition ${ }^{32}$ or partial melting of the drug crystalline form. ${ }^{31}$ Finally, MTX has a short recrystallization peak at $\approx 238-247{ }^{\circ} \mathrm{C}$, which precedes its thermal decomposition at $252{ }^{\circ} \mathrm{C}$. In general, the MTX thermogram displays gradual, ongoing crystallization, throughout the entire observation. Thus, the positive enthalpy, or absorbed heat, is constantly decreasing.
The addition of the drug to the cast silk solution suggests variable interactions between MTX and fibroin upon film drying. When comparing the DSC curves for silk-based films with and without the MTX, independently of the phosphorylation degree of the material, a similar trend of emerging MTX-derived thermal peaks was observed. The three main events, developed as only MTX powder had been heated, are depicted in Figure 4. Consequently, addition of the drug to the nonphosphorylated material induced the formation of a pseudomelting peak at $150{ }^{\circ} \mathrm{C}$ with a partial decomposition at $240-250{ }^{\circ} \mathrm{C}$ (designated by filled $(>)$ and empty $(D)$ arrows, respectively, in Figures 3 and S4 in the Supporting Information). MTX incorporation also shifted the main decomposition endotherm. This shift was significant for the $0 \%$ phosphorylation material cast at pH $7.2\left(280 \rightarrow \approx 249{ }^{\circ} \mathrm{C}\right)$, but less pronounced for the other materials (Figures S3D and S4D in the Supporting Information). Moreover, a clear decrease in the energy absorption $\left(E_{\mathrm{abs}}\right)$ was evident for all, except $60 \%$ modified and near neutral $\mathrm{pH}$-cast matrixes (compare Figures 2, 3, and S3 and S4 in the Supporting Information). Acidic $\mathrm{pH}$ cast materials of $0 \%$ and $15 \%$ phosphorylation demonstrated slight and more pronounced increase of $E_{\mathrm{abs}}$ upon MTX addition, respectively. $30 \%$ and $60 \%$ material types had mainly and highly decreased $E_{\text {abs }}$, respectively, with MTX incorporated. However, it cannot be concluded that the stronger drug-polymer interaction is evident for $7.2 \mathrm{pH}$ derived materials, based solely on the presented DSC findings.

3.4. In Vitro Release Profiling of Incorporated MTX. The structure of the material influences the incorporated MTX release profile. Prepared phospho-fibroin films were incubated in PBS with or without protease (porcine pancreatic elastase, termed as PPE solution). It is important to mention that no methanol treatment was performed prior to incubation. From our previous work, it is known that the pretreatment of the material with methanol can lead to a significant loss of incorporated drug (up to $55 \%$ of its initial content ${ }^{7}$ ). Thus, it is important to carefully choose protocols that preserve the drug prior to its actual release.

Since preliminary tests with MTX indicated rapid drug dissolution (data not shown), a short-term profiling with frequent sampling was conducted. The release profiles, depicted 

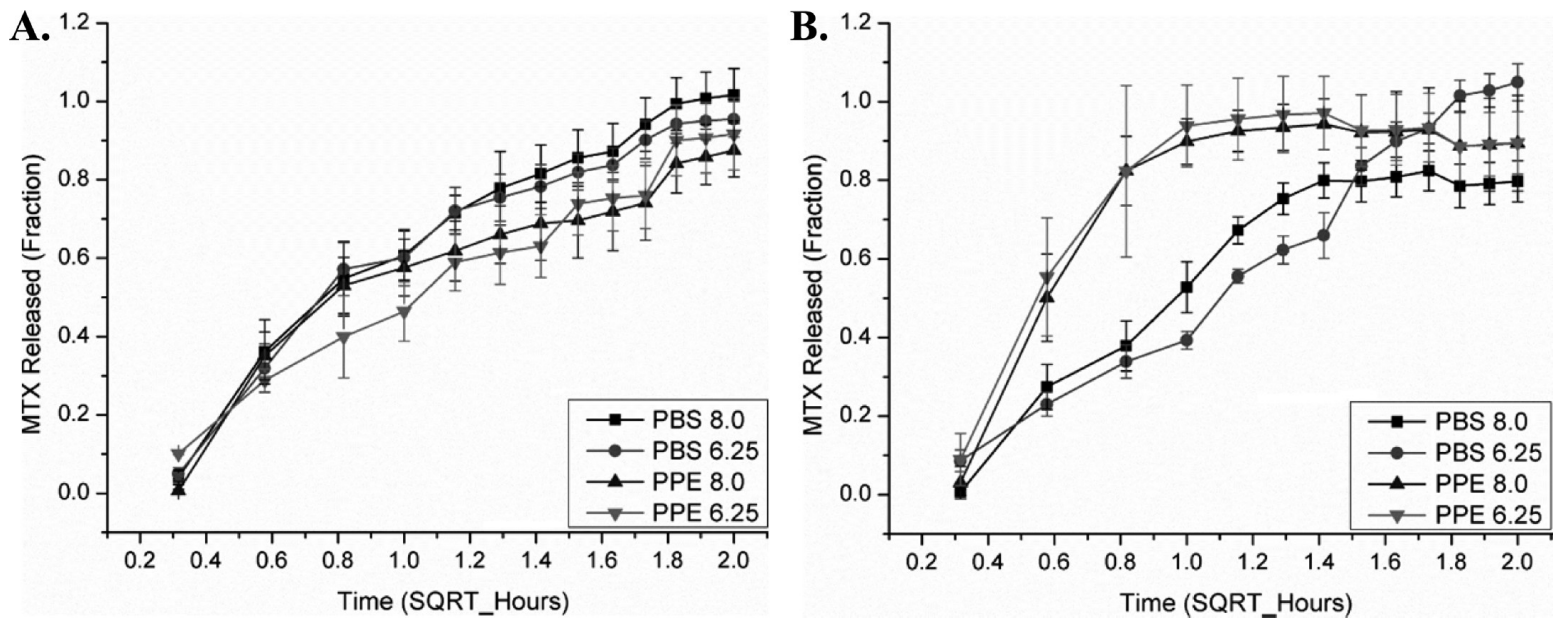

Figure 5. Release profiling of silk fibroin films with incorporated MTX. (A) Fibroin films cast at pH 7.2. (B) Fibroin films cast at pH 3.5. Each curve is an averaged value of the four discrete profiles, corresponding to $0 . .60 \%$ phosphorylated material. Examples of individual release profiles are presented in Figure S6 in the Supporting Information.

in Figure 5, reveal several important conclusions about the drug dissipation from the films. For all incubation conditions, the release of $80 \%$ of MTX was achieved within $2 \mathrm{~h}$ and there is no significant difference between PBS- or PPE-mediated release for neutral $\mathrm{pH}$-cast films. A different profile was seen for the acidic $\mathrm{pH}$ derived materials, where protease facilitated drug dissolution (Figure 4B). In the latter case, it is possible to denote the burst phase during the first hour of incubation, resulting in nearly complete drug release $(>90 \%)$. It is worth mentioning that each individual curve in Figure 4 results from the average of four independent profiling experiments, corresponding to $0 \%, 15 \%, 30 \%$, and $60 \%$ of phosphorylation content. Such representation was chosen because of the existence of considerable similarity between discrete release profiles for each matrix type (Figure S6 in the Supporting Information). Thus, for simplicity of the display, only averaged profiling curves for two major matrix types (neutral versus acidic $\mathrm{pH}$ cast) were presented, which nevertheless does not mean that the later reported kinetic values resulted from the calculation, involving cross-averaging of materials with varying phosphorylation.

Two theoretical approaches were implemented in order to better understand the release profiling of MTX from the phosphorylated materials, namely, Ritger-Peppas semiempirical and Higuchi models. ${ }^{33-35}$ For Ritger-Peppas, the constant $K_{\mathrm{RP}}$ and diffusion (or release exponent) $n$ values were estimated, similarly to the $K_{\mathrm{H}}$ diffusion value for Higuchi method.

The release mechanism and characteristics of both macromolecular network system and the drug can be deduced from $n$ and $K_{\mathrm{RP}}$ values by applying the Ritger-Peppas (RP) model to release profiles. Software-given $n$ values suggest super Case-II transport $^{36}$ for all the films incubated at $\mathrm{pH} 8.0$ (Figure 6A). Near-neutral pH-cast matrixes, incubated in PBS at pH 6.2, also demonstrate super Case-II transport values. Nevertheless these are very similar in between and close to the values characterizing a Case-II mechanism (for which $n=1 ;{ }^{37}$ average of the presented four amounts is $1.184 \pm 0.036$; Figure 6B). Other materials, cast at $\mathrm{pH} 7.2$ and $\mathrm{pH} 3.5$ and immersed in PPE and PBS, respectively, have an anomalous release mechanism (for which the inequality $0.5<n<1.0$ holds). Finally, $\mathrm{pH}$ 3.5-cast and $\mathrm{pH}$ 6.2 PPE immersed films again demonstrate a super Case-II release process. Importantly, $n$ values were not available for all the conditions examined. For all the materials in both casting groups, $\mathrm{pH}$ 8.0 PPE-assisted MTX release resulted in an initial burst phase that was so great that it rendered it impossible to apply $\mathrm{RP}$ modeling. Accordingly, MTX release from $15 \%$ and $30 \%$ modified matrixes, acidic $\mathrm{pH}$ cast, in $\mathrm{pH}$ 6.2 PPE-assisted incubation generated drug burst, noncompliable with RP conditions. ${ }^{37}$ Anomalous transport points to a complex release process, resulting from coupling of solvent diffusion into the material and its subsequent relaxation. ${ }^{38}$ Case-II and super Case-II mechanisms relate to the state of rapid solvent mobility due to increased polymer relaxation, ${ }^{37,39}$ provoking massive release of entrapped compound. The only difference between the latter two situations is that, in a super Case-II system type, saturation of the release curve is reached faster.

MTX diffusion values from the RP model, $K_{\mathrm{RP}}$, are presented in Figure 6C,D. In the $\mathrm{RP}$ model, $\mathrm{pH}$ 8.0, PBS-immersed matrixes of both casting groups seem to release the drug more easily upon lesser phosphorylation, although for neutral $\mathrm{pH}$ cast this tendency is more prominent (Figure 6C). For incubation at $\mathrm{pH}$ 6.2, both PBS- and PPE-immersed matrixes of the 7.2-casting group showed the aforementioned trend (Figure 6D). Surprisingly, the PPE-mediated diffusion subgroup manifested decreased $K_{\mathrm{RP}}$ values. The 3.5-casting group in PBS incubation did not display a considerable bias, and PPEincubated values were high (Figure 6D). It can be seen that $K_{\mathrm{RP}}$ values for incubation $\mathrm{pH} 6.2$ substantially repeat the tendency of $n$ values (compare panels $\mathrm{B}$ and $\mathrm{D}$ of Figure 6).

The Higuchi model derived diffusion parameter, $K_{\mathrm{H}}$, is depicted in Figure 7. Being a more simplified model, the Higuchi model made it possible to fit the empirical data for all of the conditions. Thus, $K_{\mathrm{H}}$ was obtained directly from the fitting algorithm. From the incubation buffers of two discrete $\mathrm{pH}$ values it can be concluded that, akin to $K_{\mathrm{RP}}, K_{\mathrm{H}}$ values undergo gradual increase as modification levels drop (Figure 7). But the $K_{\mathrm{H}}$ increment within each group is more prominent than that of $K_{\mathrm{RP}}$. The clear exception is constituted by a $\mathrm{pH}$ 3.5cast group of materials, incubated with PBS, showing somewhat decreased diffusion of MTX within a group, as a function of phosphorylation. It can be also stated that $\mathrm{pH} 8.0$ facilitates drug release. 

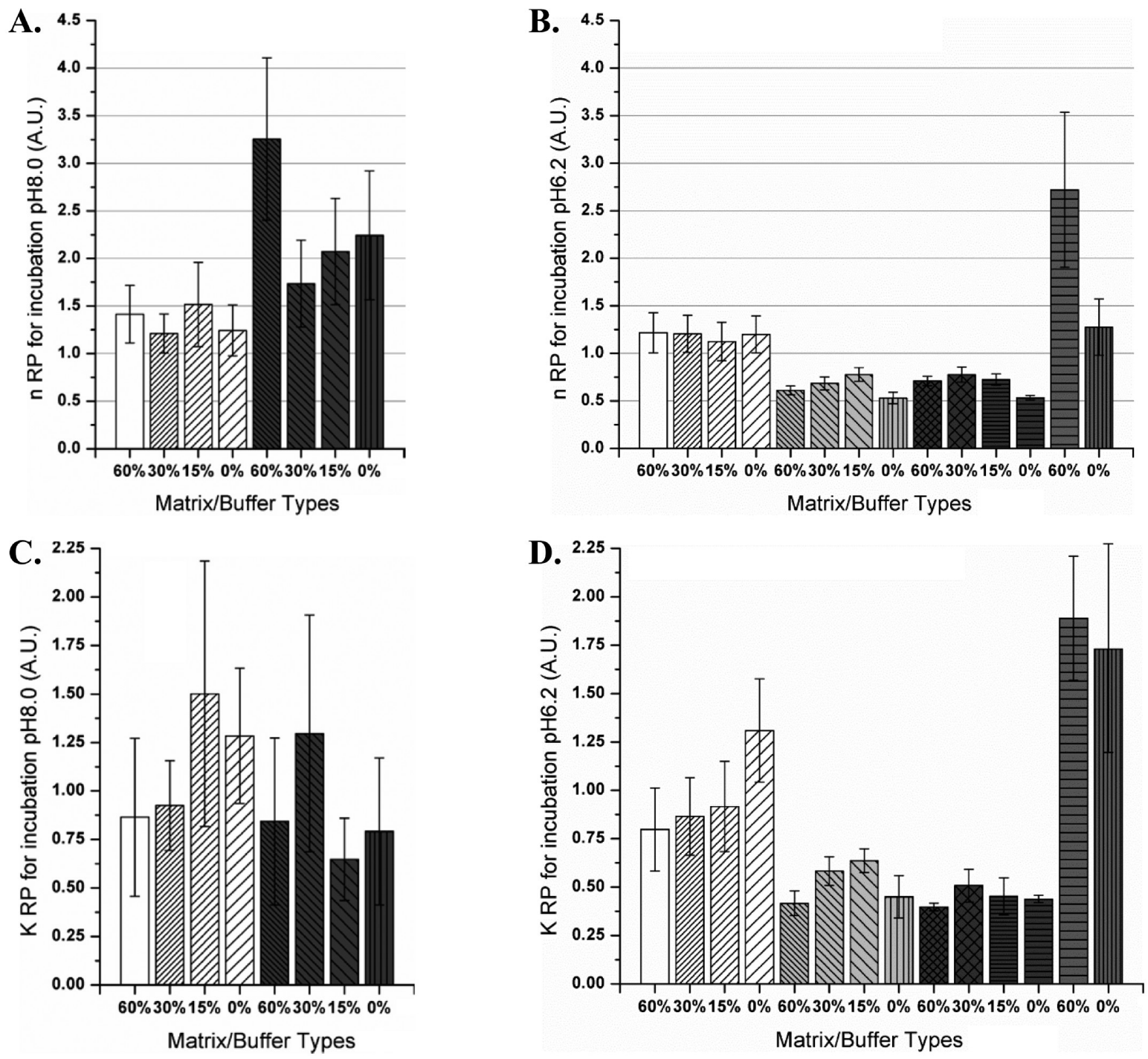

$\mathrm{pH} 7.2$-cast, PBS incubated

pH 7.2-cast, PPE incubated

pH 3.5-cast, PBS incubated

pH 3.5-cast, PPE incubated

Figure 6. Kinetic values, obtained from substitution of MTX release profiling data to the Ritger-Peppas (RP) model. The incubation of films in two distinct media (PBS or PPE) was done. Two discrete $\mathrm{pH}$ values of 8.0 or 6.2 were used. (A, B) Release exponent $n$ values for different phosphorylated silk fibroin films, computed by model. Direct output of a fitting software. (C, D) For different matrixes, RP model-derived diffusion significative, $K_{\mathrm{RP}}$, was calculated substituting $n$ values to the empirical equation, described previously. ${ }^{34}$ Data are reported with standard error and based on one release experiment with double sampling.

Based on statistical analysis, performed for $K_{\mathrm{RP}}$ and $K_{\mathrm{H}}$, it is evident that for $K_{\mathrm{RP}}$ no significant differences were observed among values of two major types of MTX-loaded films (7.2versus 3.5-cast). The phosphorylation level does not influence $K_{\mathrm{RP}}$, yet the incubation solutions do. Specifically, $\mathrm{pH}$ 7.2-cast matrixes of $60 \%$ modification, immersed in $\mathrm{pH} 6.2 \mathrm{PPE}$, correspond to the lowest $K_{\mathrm{RP}}$, and this value is different from all other conditions, conversely to $\mathrm{pH} 3.5$-cast, nonmodified matrixes, incubated in $\mathrm{pH} 6.2 \mathrm{PPE}$, where $0 \%$ and $60 \%$ correspond to the highest $K_{\mathrm{RP}}$. $K_{\mathrm{H}}$ value analysis reveals that no differences were observed among values of two major types of MTX-loaded films, considering percentage of degree modification ( $0 . .60 \%$ phosphorylation), however, various incubation solutions were significantly different. Independently of $\mathrm{pH}$ value (3.5 or 7.2 ) of the cast films, no differences among modification degree were encountered, while all incubation solutions observed were different among themselves.
3.5. Indirect Contact Effect on Cell Proliferation. According to the literature ${ }^{40,41}$ and our previous experience, ${ }^{7}$ elevated hydrophilicity disfavors cell attachment. Therefore, it was decided to evaluate the bioactivity of the films on mammalian cells by indirect contact. MTX-loaded films were incubated with cell culture medium as described, allowing the MTX to release into the medium. Cells were then cultivated in contact with the preconditioned medium, and their proliferation was monitored. Based on Figure 8 it is evident that neutral-cast materials possess higher MTX retention than their acidic $\mathrm{pH}$ cast counterparts. As expected, MTX acted as a nonproliferative agent. The proliferation rate was lower when the MTX release was higher. Additionally, films with higher extent of phosphorylation were able to retain the drug for longer time. This conclusion is clear from both casting $\mathrm{pH}$ values, however, in the neutral-derived films the trend falls within statistical error, while in the acidic $\mathrm{pH}$ derived it does not. 


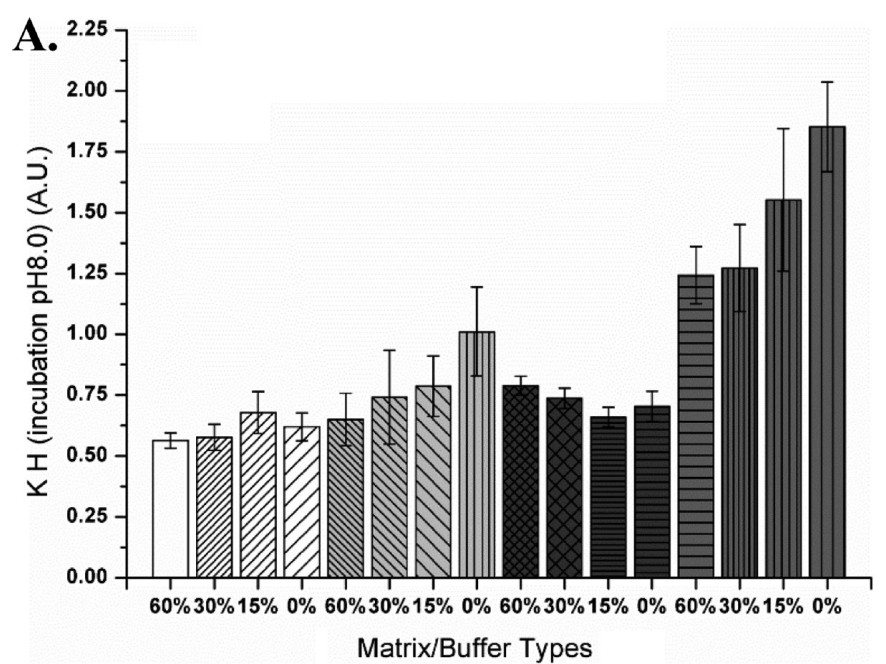

$\mathrm{pH}$ 7.2-cast, PBS incubated

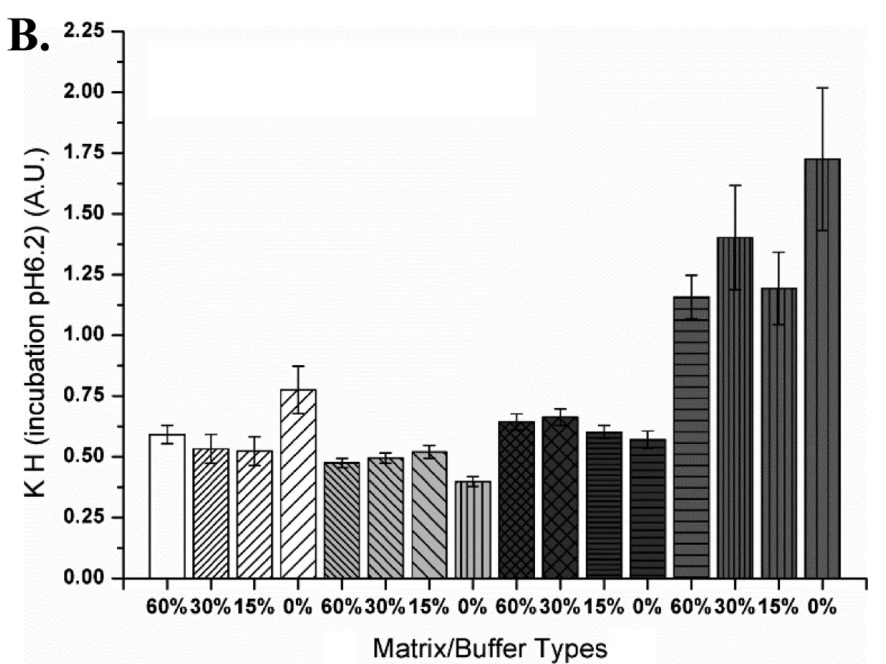

pH 3.5-cast, PBS incubated

pH 3.5-cast, PPE incubated

Figure 7. Kinetic values, obtained from substitution of MTX release profiling data to the Higuchi model. The incubation of films in two distinct media (PBS or PPE) was done. Two discrete $\mathrm{pH}$ values, 8.0 and 6.2, were used. Higuchi diffusion, $K_{\mathrm{H}}$, values for different phosphorylated silk fibroin films were computed by the corresponding model. Direct output of a fitting software. Data are reported with standard error and based on one release experiment with double sampling.
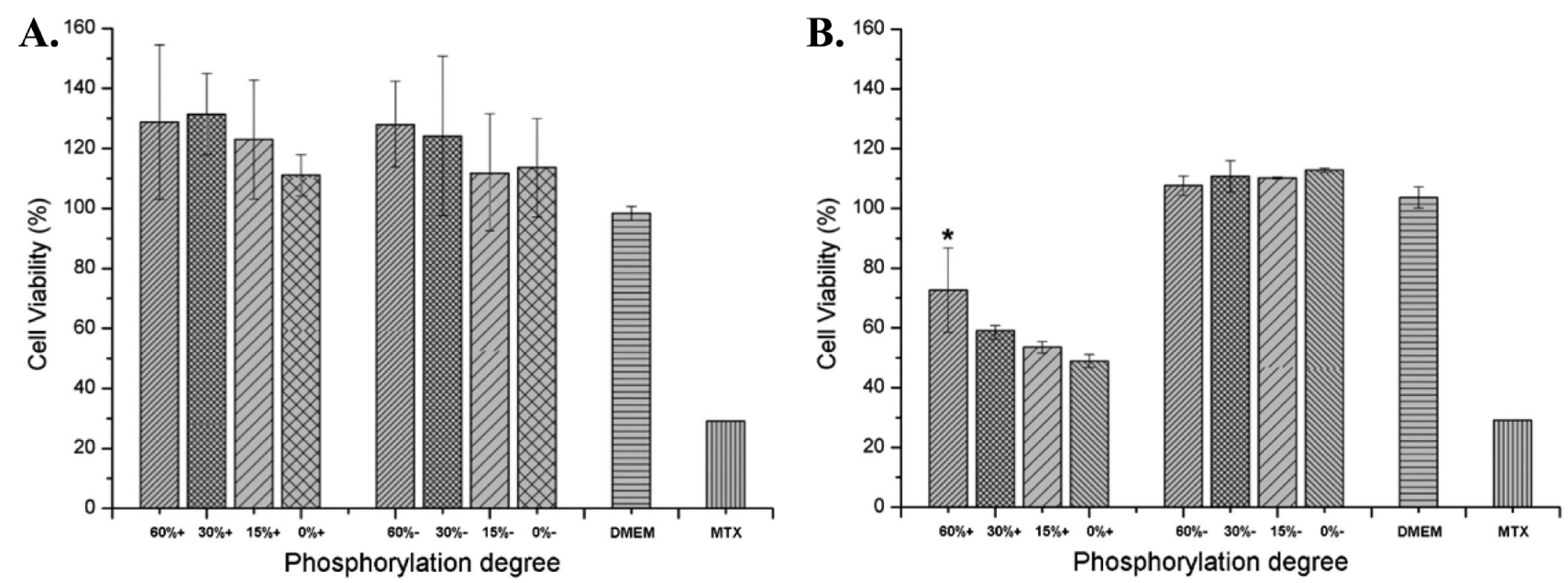

Figure 8. Viability of Caco-2 cell line, cultivated on lixiviates, derived from $6 \mathrm{~h}$ incubation of growth medium with silk fibroin MTX-loaded films. (A) $\mathrm{pH}$ 7.2-cast films. (B) $\mathrm{pH}$ 3.5-cast films. "+" and "-" denote the MTX-loaded or -devoid fibroin materials. DMEM = cell growth medium only, a positive control. MTX = methotrexate at $0.2 \mathrm{mg} / \mathrm{mL}$ concentration, a negative control. Statistically significant difference is denoted by an asterisk.

\section{DISCUSSION}

The current research examined the aspects of MTX-silk fibroin interactions in a changing environment of solution $\mathrm{pH}$ and silk phosphorylation levels. Owing to the hydrophobic nature of silk fibroin, it was our working hypothesis to examine whether a prolonged, time-controlled release of an incorporated, relatively nonhydrophilic drug, ${ }^{42}$ MTX, could be accomplished. The common practices are encapsulations of compounds into environments of similar hydrophobicity or hydrophilicity. A considerable amount of examples can be found in the literature (ref 43 and references within), supporting this notion. From this perspective, the compartment of the fibroin matrix was assumed to be suitable for MTX incorporation. The basis for sustained drug release was theoretically regarded to its low solubility in aqueous solutions. Hence, by tailoring silk hydrophobicity through its chemical alterations a trial was made to create the conditions of favored MTX retention within a fibroin matrix.

The mechanism of fibroin self-association (whether during natural spinning process or in the cast regenerated fibroin solutions) was postulated to be a thermodynamically favored $\beta$ sheet hydrophobic aggregation. ${ }^{44,45}$ It was also established that silk fibroin phosphorylation impedes fine $\beta$-sheet stacking in the secondary protein conformation. ${ }^{7,46}$ In this work, different blends (or batches) of matrixes were used for all the studies because the physical amount of the elaborated material makes it very hard to use in all three tests. Moreover, we would like to demonstrate the repeatability and consistency of the production method. As can be seen, very similar materials are obtained (in terms of phosphorylation, Table 1) for different batches. To examine the nature of occurring interactions, two distinct $\mathrm{pH}$ values were tested (3.5 versus 7.2 ). At low $\mathrm{pH}$, actual net charges of both protein and drug appear to be considerably higher than their theoretical values. The measured $z$ values 
were higher than could be expected, based on the theoretical estimation (Figures S1 and S2 in the Supporting Information). This may be attributed to increased $R_{\mathrm{H}}$ estimation by DLS, resulting in decreased $D_{0}$ (see section 2.6), since the possible augmentation of $\mu$ is inconsistent with the tendency, previously reported for this variable. ${ }^{47}$ In particular, fibroin is known to rapidly form aggregates below $\mathrm{pH} 4.59 .^{28}$ These less soluble structures decrease diffusion rate $\mathrm{rat}^{23}$ and result in higher estimation of a hydrodynamic radius, which leads to the calculation of elevated net charge. The hydrophobic clustering per se could however cause enhanced charge accumulation, ${ }^{48}$ in this case, positive. Given the fact that at nearly neutral $\mathrm{pH}$ electrostatic repulsion between both components should also exist, it is necessary to clarify why MTX affinity to fibrous film was significantly lower at acidic $\mathrm{pH}$. It is possible that, while forming a dense, $\beta$-sheet clustering, MTX is mainly excluded from the resulting structure, since no favorable electrostatic interaction is present, or it is not strong enough.

DSC analysis further enforces the observation of varying polymer-drug interactions as a function of $\mathrm{pH}$. For silk fibroin, its self-assembly ${ }^{28}$ during the drying process is comparable to that induced by methanol treatment of dried fibrous materials, obtained by solvent casting. ${ }^{7,29,49,50}$ The incorporation of phosphate groups causes $T_{\mathrm{g}}$ to shift slightly to lower values, inducing a plasticization effect ${ }^{51}$ (Figures 2 and S3 in the Supporting Information). Extensive phosphorylation (60\%) eliminates $T_{\mathrm{g}}$ completely (Figure 2 ); moreover, $T_{\mathrm{g}}$ cannot be determined precisely (or possess a single value) in semicrystalline polymers like silk fibroin and similar ones. ${ }^{52,53}$ Broad glass transition curves are ascribed to the composition heterogeneity of the elaborated materials, composed of polymer blends. For that reason only the onset of glass transition is marked in the DSC curves. Additionally, the phosphorylation per se reduces $\beta$ structure formation, ${ }^{46}$ thus decreasing crystallinity and masking possible $T_{\mathrm{g}}$ by broadening distribution of relaxation times in the polymer.

Maximal MTX dehydration occurred at $91{ }^{\circ} \mathrm{C}$, however this step was a part of a pretreatment phase of DSC experiment (see section 2.7) and, therefore, is not seen during the recorded measurement. The thermal results and the characteristic peaks indicate that the drug used was of its trihydrate form. ${ }^{32}$ MTXderived pseudomelting peak and the decomposition peaks shift to lower temperatures for $\mathrm{pH}$ 7.2-cast films. The shift of both pseudomelting ( $)$ and recrystallization coupled to decomposition $(D)$ endotherms of MTX toward lower temperatures $\left(175 \rightarrow 150{ }^{\circ} \mathrm{C}\right.$ and $252 \rightarrow 240-250{ }^{\circ} \mathrm{C}$; Figures 3 and S5 in the Supporting Information) suggests strong drug-polymer interaction. ${ }^{31}$ Of special magnitude is the MTX pseudomelting endotherm observed in nonmodified, neutral-cast fibroin (Figure S5A in the Supporting Information), traversing other curves. The cause of such behavior is unknown and cannot be explained on solely hydrophobicity basis, since the same film type, corresponding to acidic casting and thus considered more hydrophobic (Figure S5B in the Supporting Information), shows no such profound peak. Much less evident is the thermal event, encountered for $15 \%$-phosphorylated silk. More extensively modified matrixes of $\mathrm{pH} 7.2$ show no MTX-derived events. The drug pseudomelting peak, although weakly pronounced for $\mathrm{pH} 3.5$-cast films ( $0 \%$ and $15 \%$ ), is also shifted. This is the only peak type, clearly distinguishable for the acidic $\mathrm{pH}$ cast materials (Figure S5 in the Supporting Information). MTX decomposition-derived peaks are present for both discrete $\mathrm{pH}$ values at $0 \%$-modified fibroin only. The described differences in DSC results, involved with various materials, could be attributed to the different aggregate state of both constituting proteins and MTX in the samples. ${ }^{31}$ Additional phenomena, ${ }^{54}$ such as film thickness, intermolecular mobility of chains within the polymer, or its previous thermal history, probably explain the example of out-of-trend DSC curve for $30 \%$ modified fibroin, acidic-cast (Figures S4B and S5B in the Supporting Information).

In vitro release profiling of MTX made it possible to affirm that the release process is somewhat more facilitated from the matrixes elaborated at acidic $\mathrm{pH}$. The release exponent $n$ values were not always consistent with those expected for a specific material type, for example, anomalous-type release for $\mathrm{pH}$ 7.2and 3.5-cast and $\mathrm{pH}$ 6.2 PPE- or PBS-incubated, respectively; Figure $6 \mathrm{~B}$. In that situation one would expect to obtain higher $n$, corresponding to (super) Case-II mechanism, especially in PPE-assisted process. Yet, the actual inability to apply $\mathrm{RP}$ modeling on the PPE-mediated profiles for $\mathrm{pH} 8.0$ incubated matrixes, both neutral- and acidic-cast, underlines a strong burst release phase that surpasses $60 \%$ of total drug amount, initially found in the fibroin. Thus, at optimum $\mathrm{pH}$, PPE promotes the drug release from both major groups of materials. Moreover, for $\mathrm{pH}$ 3.5-cast films even at $\mathrm{pH}$ incubation of 6.2, in PPEmediated process, $n$ values surpass those of $\mathrm{pH} 7.2$-cast films. Again, not all the $n$ values were calculated, due to RP model restriction (but only those corresponding to $60 \%$ and $0 \%$ modifications, last two columns on the right in Figure 6B), which signifies a sizable burst effect upon initial MTX release. The burst is also seen at PBS incubation of $\mathrm{pH} 8.0$ for 3.5-cast films (Figure 6A). This phenomenon of elevated burst in acidified fibroin-derived materials needs explanation. Similarly to the reported findings, ${ }^{55,56}$ increased migration of MTX during the drying of cast films may result in a nonhomogeneous distribution of drug in the formed matrix and provoke a burst release. Another plausible cause for lesser MTX retention inside the acidified-cast silk matrixes is their increased (in comparison with neutral $\mathrm{pH}$-cast matrixes) heterogeneity. Heterogeneity may result from formation of cracks or perforations during the device fabrication. Indeed, $\mathrm{pH}$ 3.5-cast materials were more brittle than their $\mathrm{pH}$ 7.2-cast counterparts. Examples are known of phenomena when formulations have been made by solvent evaporation and an increased removal of the solvent causes elevated porosity. ${ }^{57,58}$ All of the above considerations make the statement regarding super Case-II release (bearing release exponent $n>1$ ) of MTX from the currently fabricated materials quite expected. Besides, super Case-II-controlled release was already observed for caffeine-loaded karaya gum hydrophilic matrixes, ${ }^{36}$ alprenolol-incorporated cellulose-derived tablets; ${ }^{59}$ cross-linked chitosan membranes in aqueous media swelled in a super Case-II manner. ${ }^{60}$

As for diffusion-related constants, both models show significant difference of the derived values for neutral solution-cast films, but not for acidic one. The two kinetic models used can be compared through their $K_{\mathrm{RP}}$ and $K_{\mathrm{H}}$ values, as neither $K_{\mathrm{RP}}$ nor $K_{\mathrm{H}}$ has obvious definition (although describing similar concepts). $K_{\mathrm{RP}}$ alternatively can be seen as an interaction parameter between a drug and the material harboring it. ${ }^{33}$ Within each model, RP did not demonstrate differences among $K_{\mathrm{RP}}$ values of the films, yet statistical differences among $K_{\mathrm{H}}$ values of films, obtained by the Higuchi model, seem to be more discriminative. This may stem from the nature of calculations involved in both approaches. $K_{\mathrm{H}}$ parameter is given by fitting software directly, while $K_{\mathrm{RP}}$ is 
derived from $n$. Moreover, RP approach implies that only the profile data, obtained from $60 \%$ release of the initial content, may be included in calculations, ${ }^{33-35}$ which does not hold for the Higuchi model, where the full range of release values can be used.

Wilcoxon's matched pairs test showed that, for neutral-cast materials, $K_{\mathrm{RP}^{-}}$and $K_{\mathrm{H}^{-}}$-derived values are significantly different. Based on $t$-test, the Ritger-Peppas model reports no differences in $K_{\mathrm{RP}}$ values among films, yet Higuchi shows statistical differences among $K_{\mathrm{H}}$ values of films.

Finally, the indirect contact assay results support the observations that acidified solution-cast materials release the drug intensively, whereas neutral solution-derived do not. Importantly, a negative correlation between phosphorylated content and MTX release is evident for the acidified formulations. This underlines the importance of phosphorylation in disrupting $\beta$-sheet structures, as reported previously, ${ }^{7,46}$ by creating a more favorable environment for MTX retention.

In summary, it can be concluded that our initial assumption for the enhanced MTX retention within a dense, acidified hydrophobic matrix of silk fibroin was not proved. We were not able to establish time-controlled release of the drug, although the term "time-controlled" itself is not precisely defined, and there exists a distinction between burst release and short-term controlled release, observed for several systems. ${ }^{61}$ In our case the statement that a prolonged time-controlled release was not established will be more correct. According to the Biopharmaceutics Classification System (BCS), MTX falls in more than one category of compounds' solubility: ${ }^{42}$ it can be highly or less soluble, depending on the experimental conditions. Indeed, MTX solubility mainly depends on the ionization of its $\alpha$ - and $\gamma$-carboxylic groups $^{62}\left(\mathrm{p} K_{1} \approx 3.22\right.$ and $\mathrm{p} K_{2} \approx 4.53$, respectively $)^{63}$ and slightly on the state of a basic pteridine moiety $\left(\mathrm{pK}_{3} \approx 5.62\right){ }^{63}$ Hence, during casting solution preparation, the partial aggregation of the added solubilized MTX to acidified silk fibroin solution occurred, corroborating previous observations of MTX precipitation as a function of $\mathrm{pH} .{ }^{62}$ Likely drug migration to the superficial layers of forming materials during their drying caused nonuniformity of its distribution. Thus, despite the increase of protein selfaggregation at acidic $\mathrm{pH}$, it does not enhance the drug retention inside the film matrix. Actually, a lesser polymerdrug association was obtained, though not because of decreased affinity of MTX to the fibroin, but resulting from heterogeneity of its final distribution in the films. Kinetic parameters, obtained throughout the current study, points to basic $\mathrm{pH}$ and PPE enzyme as factors, facilitating the drug release. It is no surprise that increased ionization or matrix degradation promotes MTX solubilization or the release from the films. However, with respect to PPE, the option to drive the MTX release under proteolysis is of questionable value, so far as significant burst effect occurred. If the designed material would possess a prolonged time-controlled release per se, PPE contribution to the process would probably be considered as beneficial. Future perspectives on enhancing phosphorylated silk-based films may include physical manipulations on the cast material, using lesser molecular weight fibroin as a source for downstream processing, or adding plasticizers like glycerol. The treatments mentioned above were found to increase dried films' plasticity, ${ }^{64}$ flexibility and water retention, ${ }^{65}$ or alter release rate of the incorporated compound from a film and the rate of film degradation. ${ }^{66}$ Later, if the drug is to be added, it may experience different (desirably prolonged) release kinetics.

On the contrary, nearly neutral solution-casting produced materials with slower drug release. The explanation for decreased density of those fabricated films and the following more uniform MTX incorporation, resulting in its slower dissipation, is quite reasonable. Several works reported a connection between elevated content of $\beta$-sheet crystals and the formation of high packing density in silk fibroin. ${ }^{67-70}$ Crystallinity is directly related to $\beta$-sheet hydrophobic stacking, and in the silk solution it is favored at dehydration, ${ }^{68}$ shear stress, ${ }^{71}$ heating, ${ }^{28}$ and $\mathrm{pH}$ drop, ${ }^{28}$ among other modes. The conclusion for decreased density of $\mathrm{pH}$ 7.2-cast films stems from previous observations of decreased $\beta$-sheet amounts in phosphorylated fibroin by circular dicroism ${ }^{46}$ and deconvolved FTIR spectra, reflecting on secondary structure analysis. ${ }^{7}$ Moreover, being that none of the above treatments for crystallinity induction was done on neutral pH-cast films, they are considered to possess a less tight structure. Since the electrostatic interactions are considered to be mainly repulsive in both cases (Figures 1 and $\mathrm{S} 1$ and S2 in the Supporting Information), the matrix structure has a determinative effect on the drug retention.

\section{ASSOCIATED CONTENT}

\section{S Supporting Information}

Figures depicting theoretical estimation of silk fibroin and methotrexate (MTX) charges as a function of $\mathrm{pH}$; experimental estimation of silk fibroin and MTX charges as a function of $\mathrm{pH}$; pairwise comparisons of DSC curves corresponding to two main types (acidic- or neutral-pH cast) of elaborated materials; a group representation of DSC curves corresponding to the two main types (acidic- or neutral-pH cast) of elaborated materials, together with MTX only powder; and representative examples of individual profiling curves of MTX release that served as a source for averaging. This material is available free of charge via the Internet at http://pubs.acs.org.

\section{AUTHOR INFORMATION}

\section{Corresponding Author}

*Tel: +351 253604 409. Fax: +351 253604 429. E-mail: artur@deb.uminho.pt.

\section{Notes}

The authors declare no competing financial interest.

\section{ACKNOWLEDGMENTS}

The authors would like to acknowledge the support, granted by European NOVO Project, Contract No. FP7-HEALTH 2011two-stage 278402. This work was partially supported by FEDER through POFC-COMPETE and by national funds from FCT through the projects PEst-C/BIA/UI4050/2011 (CBMA). V.V. also wants to thank Dr. Cláudia Botelho for her helpful discussion and comments made during the critical reading of the manuscript.

\section{REFERENCES}

(1) Naskar, D.; Barua, R. R.; Ghosh, A. K.; Kundu, S. C., Introduction to silk biomaterials. In Silk Biomaterials for Tissue Engineering and Regenerative Medicine, 1st ed.; Kundu, S., Ed.; Elsevier: 2014; pp 2327.

(2) Kundu, S. C.; Kundu, B.; Talukdar, S.; Bano, S.; Nayak, S.; Kundu, J.; Mandal, B. B.; Bhardwaj, N.; Botlagunta, M.; Dash, B. C.; 
Acharya, C.; Ghosh, A. K. Invited review nonmulberry silk biopolymers. Biopolymers 2012, 97 (6), 455-67.

(3) Kundu, B.; Rajkhowa, R.; Kundu, S. C.; Wang, X. Silk fibroin biomaterials for tissue regenerations. Adv. Drug Delivery Rev. 2013, 65 (4), 457-70.

(4) Numata, K.; Kaplan, D. L. Silk-based delivery systems of bioactive molecules. Adv. Drug Delivery Rev. 2010, 62 (15), 1497-508.

(5) Bhattacharjee, M.; Schultz-Thater, E.; Trella, E.; Miot, S.; Das, S.; Loparic, M.; Ray, A. R.; Martin, I.; Spagnoli, G. C.; Ghosh, S. The role of $3 \mathrm{D}$ structure and protein conformation on the innate and adaptive immune responses to silk-based biomaterials. Biomaterials 2013, 34 (33), 8161-71.

(6) Westheimer, F. H. Why nature chose phosphates. Science 1987, 235 (4793), 1173-8.

(7) Volkov, V.; Vasconcelos, A.; Sarria, M. P.; Gomes, A. C.; CavacoPaulo, A. Phosphorylation of silk fibroins improves the cytocompatibility of silk fibroin derived materials: A platform for the production of tuneable material. Biotechnol. J. 2014, 9 (10), 1267-78.

(8) Śmiechowski, M. Theoretical pKa prediction of O-phosphoserine in aqueous solution. Chem. Phys. Lett. 2011, 514 (4-6), 123-9.

(9) Mandell, D. J.; Chorny, I.; Groban, E. S.; Wong, S. E.; Levine, E.; Rapp, C. S.; Jacobson, M. P. Strengths of hydrogen bonds involving phosphorylated amino acid side chains. J. Am. Chem. Soc. 2007, 129 (4), 820-7.

(10) Duthie, S. J. Folic-acid-mediated inhibition of human coloncancer cell growth. Nutrition 2001, 17 (9), 736-7.

(11) Belur, L. R.; Boelk-Galvan, D.; Diers, M. D.; McIvor, R. S.; Zimmerman, C. L. Methotrexate Accumulates to Similar Levels in Animals Transplanted with Normal versus Drug-resistant Transgenic Marrow. Cancer Res. 2001, 61, 1522-6.

(12) Widemann, B. C.; Adamson, P. C. Understanding and managing methotrexate nephrotoxicity. Oncologist 2006, 11 (6), 694-703.

(13) Banerjee, D.; Mayer-Kuckuk, P.; Capiaux, G.; Budak-Alpdogan, T.; Gorlick, R.; Bertino, J. R. Novel aspects of resistance to drugs targeted to dihydrofolate reductase and thymidylate synthase. Biochim. Biophy. Acta 2002, 1587 (2-3), 164-73.

(14) Miao, B.; Song, C.; Ma, G. Injectable thermosensitive hydrogels for intra-articular delivery of methotrexate. J. Appl. Polym. Sci. 2011, 122 (3), 2139-45.

(15) Zhang, X.; Chen, F.; Ni, J. A novel method to prepare magnetite chitosan microspheres conjugated with methotrexate (MTX) for the controlled release of MTX as a magnetic targeting drug delivery system. Drug Delivery 2009, 16 (5), 280-8.

(16) Cascone, M. G.; Lazzeri, L.; Carmignani, C.; Zhu, Z. Gelatin nanoparticles produced by a simple $\mathrm{W} / \mathrm{O}$ emulsion as delivery system for methotrexate. J. Mater. Sci.: Mater. Med. 2002, 13 (5), 523-6.

(17) Nogueira, D. R.; Tavano, L.; Mitjans, M.; Perez, L.; Infante, M. R.; Vinardell, M. P. In vitro antitumor activity of methotrexate via $\mathrm{pH}$ sensitive chitosan nanoparticles. Biomaterials 2013, 34 (11), 2758-72.

(18) Abdelbary, G.; Haider, M. In vitro characterization and growth inhibition effect of nanostructured lipid carriers for controlled delivery of methotrexate. Pharm. Dev. Technol. 2013, 18 (5), 1159-68.

(19) Chau, Y.; Tan, F. E.; Langer, R. Synthesis and characterization of dextran-peptide-methotrexate conjugates for tumor targeting via mediation by matrix metalloproteinase II and matrix metalloproteinase IX. Bioconjugate Chem. 2004, 15 (4), 931-41.

(20) Subia, B.; Kundu, S. C. Drug loading and release on tumor cells using silk fibroin-albumin nanoparticles as carriers. Nanotechnology 2013, 24 (3), 035103.

(21) Mathur, A. B.; Rios, C. N.; Gupta, V.; Aseh, A. Preparation and methodology of silk fibroin nanoparticles. WO 2010059963 A3, 2010.

(22) Lammel, A.; Scheibel, T.; Schwab, M.; Winter, G.; Hofer, M.; Myschik, J. Silk particles for controlled and sustained delivery of compounds. WO 2011063990 A3, 2012.

(23) Ochi, A.; Hossain, K. S.; Magoshi, J.; Nemoto, N. Rheology and dynamic light scattering of silk fibroin solution extracted from the middle division of Bombyx mori silkworm. Biomacromolecules 2002, 3 (6), 1187-96.
(24) Lehermayr, C.; Mahler, H. C.; Mader, K.; Fischer, S. Assessment of net charge and protein-protein interactions of different monoclonal antibodies. J. Pharm. Sci. 2011, 100 (7), 2551-62.

(25) Hu, X.; Wang, X.; Rnjak, J.; Weiss, A. S.; Kaplan, D. L. Biomaterials derived from silk-tropoelastin protein systems. Biomaterials 2010, 31 (32), 8121-31.

(26) Matsumoto, A.; Lindsay, A.; Abedian, B.; Kaplan, D. L. Silk fibroin solution properties related to assembly and structure. Macromol. Biosci 2008, 8 (11), 1006-18.

(27) Barltrop, J. A.; Owen, T. C.; Cory, A. H.; Cory, J. G. 5-(3Carboxymethoxyphenyl)-2-(4,5-dimethylthiazolyl)-3-(4-sulfophenyl)tetrazolium, inner salt (MTS) and related analogs of 3-(4,5dimethylthiazolyl)-2,5-diphenyltetrazolium bromide (MTT) reducing to purple water-soluble formazans As cell-viability indicators. Bioorg. Med. Chem. Lett. 1991, 1 (11), 611-4.

(28) Matsumoto, A.; Chen, J.; Collette, A. L.; Kim, U. J.; Altman, G. H.; Cebe, P.; Kaplan, D. L. Mechanisms of silk fibroin sol-gel transitions. J. Phys. Chem. B 2006, 110 (43), 21630-8.

(29) Motta, A.; Fambri, L.; Migliaresi, C. Regenerated Silk Fibroin Films: Thermal and Dynamic Mechanical Analysis. Macromol. Chem. Phys. 2002, 203 (10-11), 1658-65.

(30) Vasconcelos, A.; Freddi, G.; Cavaco-Paulo, A. Biodegradable materials based on silk fibroin and keratin. Biomacromolecules 2008, 9 (4), 1299-305.

(31) de Oliveira, A. R.; Molina, E. F.; de Castro Mesquita, P.; Fonseca, J. L. C.; Rossanezi, G.; de Freitas Fernandes-Pedrosa, M.; de Oliveira, A. G.; da Silva-Júnior, A. A. Structural and thermal properties of spray-dried methotrexate-loaded biodegradable microparticles. J. Therm. Anal. Calorim. 2013, 112 (2), 555-65.

(32) Chadha, R.; Arora, P.; Kaur, R.; Saini, A.; Singla, M. L.; Jain, D. $\mathrm{S}$. Characterization of solvatomorphs of methotrexate using thermoanalytical and other techniques. Acta Pharm. 2009, 59 (3), 245-57.

(33) Costa, P.; Sousa Lobo, J. M. Modeling and comparison of dissolution profiles. Eur. J. Pharm. Sci. 2001, 13 (2), 123-33.

(34) Ritger, P. L.; Peppas, N. A. A simple equation for description of solute release I. Fickian and non-fickian release from non-swellable devices in the form of slabs, spheres, cylinders or discs. J. Controlled Release 1986, 5 (1), 23-6.

(35) Higuchi, T. Mechanism of sustained-action medication. Theoretical analysis of rate of release of solid drugs dispersed in solid matrices. J. Pharm. Sci. 1963, 52 (12), 1145-9.

(36) Munday, D. L.; Cox, P. J. Compressed xanthan and karaya gum matrices: hydration, erosion and drug release mechanisms. Int. J. Pharm. 2000, 203 (1-2), 179-92.

(37) Ritger, P. L.; Peppas, N. A. A simple equation for description of solute release II. Fickian and anomalous release from swellable devices. J. Controlled Release 1987, 5 (1), 37-42.

(38) Alfrey, T.; Gurnee, E. F.; Lloyd, W. G. Diffusion in glassy polymers. J. Polym. Sci., Part C: Polym. Symp. 1966, 12 (1), 249-61.

(39) Lee, I. P. Kinetics of drug release from hydrogel matrices. J. Controlled Release 1985, 2, 277-88.

(40) Hezi-Yamit, A.; Sullivan, C.; Wong, J.; David, L.; Chen, M.; Cheng, P.; Shumaker, D.; Wilcox, J. N.; Udipi, K. Impact of polymer hydrophilicity on biocompatibility: implication for DES polymer design. J. Biomed. Mater. Res. A 2009, 90 (1), 133-41.

(41) Khorasani, M. T.; Moemenbellah, S.; Mirzadeh, H.; Sadatnia, B. Effect of surface charge and hydrophobicity of polyurethanes and silicone rubbers on L929 cells response. Colloids Surf., B 2006, 51 (2), $112-9$.

(42) Wu, C. Y.; Benet, L. Z. Predicting drug disposition via application of BCS: transport/absorption/ elimination interplay and development of a biopharmaceutics drug disposition classification system. Pharm. Res. 2005, 22 (1), 11-23.

(43) Fu, Y.; Kao, W. J. Drug release kinetics and transport mechanisms of non-degradable and degradable polymeric delivery systems. Expert Opin. Drug Delivery 2010, 7 (4), 429-44. 
(44) Zhou, C. Z.; Confalonieri, F.; Jacquet, M.; Perasso, R.; Li, Z. G.; Janin, J. Silk fibroin: structural implications of a remarkable amino acid sequence. Proteins 2001, 44 (2), 119-22.

(45) Winkler, S.; Kaplan, D. L. Molecular biology of spider silk. J. Biotechnol. 2000, 74 (2), 85-93.

(46) Winkler, S.; Wilson, D.; Kaplan, D. L. Controlling beta-sheet assembly in genetically engineered silk by enzymatic Phosphorylation/ Dephosphorylation, by. Biochemistry 2000, 39 (45), 14002.

(47) Bahga, S. S.; Bercovici, M.; Santiago, J. G. Ionic strength effects on electrophoretic focusing and separations. Electrophoresis 2010, 31 (5), 910-9.

(48) Dobrynin, A. V.; Rubinstein, M. Theory of polyelectrolytes in solutions and at surfaces. Prog. Polym. Sci. 2005, 30 (11), 1049-118.

(49) Magoshi, J.; Magoshi, Y.; Nakamura, S.; Kasai, N.; Kakudo, M. Physical properties and structure of silk. V. Thermal behavior of silk fibroin in the random-coil conformation. J. Polym. Sci., Polym. Phys. Ed. 1977, 15 (9), 1675-83.

(50) Magoshi, J.; Nakamura, S. Studies on physical properties and structure of silk. Glass transition and crystallization of silk fibroin. $J$. Appl. Polym. Sci. 1975, 19 (4), 1013-5.

(51) Budhavaram, N. K.; Miller, J. A.; Shen, Y.; Barone, J. R. Protein substitution affects glass transition temperature and thermal stability. $J$. Agric. Food Chem. 2010, 58 (17), 9549-55.

(52) Alves, N. M.; Mano, J. F.; Balaguer, E.; Meseguer, D. J. M.; Ribelles, J. L. Glass transition and structural relaxation in semicrystalline poly(ethyleneterephthalate): a DSC study. Polymer 2002, 43 (15), 4111-22.

(53) Narladkar, A.; Balnois, E.; Vignaud, G.; Grohens, Y. Difference in Glass Transition Behavior Between Semi Crystalline and Amorphous poly(lactic acid) Thin Films. Macromol. Symp. 2008, 273 (1), 146-52.

(54) Keddie, J. L.; Jones, R. A. L.; Cory, R. A. Size-Dependent Depression of the Glass Transition Temperature in Polymer Films. Europhys. Lett. 1994, 27 (1), 59-64.

(55) Kishida, A.; Murakami, K.; Goto, H.; Akashi, M.; Kubota, H.; Endo, T. Polymer drugs and polymeric drugs X: Slow release of Bfluorouracil from biodegradable poly $(\gamma$-glutamic acid $)$ and its benzyl ester matrices. J. Bioact. Compat. Polym. 1998, 13 (4), 270-8.

(56) Mallapragada, S. K.; Peppas, N. A.; Colombo, P. Crystal dissolution-controlled release systems. II. Metronidazole release from semicrystalline poly(vinyl alcohol) systems. J. Biomed. Mater. Res. 1997, 36 (1), 125-30.

(57) Jalil, R; Nixon, J. R. Biodegradable poly(lactic acid) and poly(lactide-co-glycolide) microcapsules: problems associated with preparative techniques and release properties. J. Microencapsulation 1990, 7 (3), 297-325.

(58) Ahmed, A. R.; Dashevsky, A.; Bodmeier, R. Reduced burst effect in drug release with solvent-treated microparticles prepared by the solvent evaporation method. Proc. Int. Symp. Controlled Release Bioact. Mater. 2000, 27, 6112.

(59) Ranga Rao, K. V.; Padmalatha Devi, K.; Buri, P. Cellulose Matrices for Zero-Order Release of Soluble Drugs. Drug Dev. Ind. Pharm. 1988, 14 (15-17), 2299-320.

(60) Gierszewska-Drużyńska, M.; Ostrowska-Czubenko, J. Mechanism of water diffusion into noncrosslinked and ionically crosslinked chitosan membranes. PCACD (Poland) 2012, 17, 59-66.

(61) Brazel, C. S.; Peppas, N. A. Mechanisms of solute and drug transport in relaxing, swellable, hydrophilic glassy polymers. Polymer 1998, 40 (12), 3383-98.

(62) Kono, K.; Liu, M.; Frechet, J. M. Design of dendritic macromolecules containing folate or methotrexate residues. Bioconjugate Chem. 1999, 10 (6), 1115-21.

(63) Szakacs, Z.; Noszal, B. Determination of dissociation constants of folic acid, methotrexate, and other photolabile pteridines by pressure-assisted capillary electrophoresis. Electrophoresis 2006, 27 (17), 3399-409.

(64) Lu, S.; Wang, X.; Lu, Q.; Zhang, X.; Kluge, J. A.; Uppal, N.; Omenetto, F.; Kaplan, D. L. Insoluble and flexible silk films containing glycerol. Biomacromolecules 2010, 11 (1), 143-50.
(65) Zhang, C.; Song, D.; Lu, Q.; Hu, X.; Kaplan, D. L.; Zhu, H. Flexibility regeneration of silk fibroin in vitro. Biomacromolecules 2012, 13 (7), 2148-53.

(66) Pritchard, E. M.; Hu, X.; Finley, V.; Kuo, C. K.; Kaplan, D. L. Effect of silk protein processing on drug delivery from silk films. Macromol. Biosci. 2013, 13 (3), 311-20.

(67) Lu, Q.; Hu, X.; Wang, X.; Kluge, J. A.; Lu, S.; Cebe, P.; Kaplan, D. L. Water-insoluble silk films with silk I structure. Acta Biomater. 2010, 6 (4), 1380-7.

(68) Wang, X.; Hu, X.; Daley, A.; Rabotyagova, O.; Cebe, P.; Kaplan, D. L. Nanolayer biomaterial coatings of silk fibroin for controlled release. J. Controlled Release 2007, 121 (3), 190-9.

(69) Motta, A.; Maniglio, D.; Migliaresi, C.; Kim, H. J.; Wan, X.; Hu, X.; Kaplan, D. L. Silk fibroin processing and thrombogenic responses. J. Biomater. Sci., Polym. Ed. 2009, 20 (13), 1875-97.

(70) Hu, X.; Kaplan, D.; Cebe, P. Dynamic Protein-Water Relationships during $\beta$-Sheet Formation. Macromolecules 2008, 41 (11), 3939-48.

(71) Wang, X.; Kluge, J. A.; Leisk, G. G.; Kaplan, D. L. Sonicationinduced gelation of silk fibroin for cell encapsulation. Biomaterials 2008, 29 (8), 1054-64. 